\title{
Article
}

\section{Lessons learned by educator and students through experiential entrepreneurship}

Simmons, Marcus

Available at http://clok.uclan.ac.uk/37946/

Simmons, Marcus ORCID: 0000-0001-6180-7105 (2021) Lessons learned by educator and students through experiential entrepreneurship. Industry \& Higher Education, 35 (4). pp. 454-459. ISSN 0950-4222

It is advisable to refer to the publisher's version if you intend to cite from the work. http://dx.doi.org/10.1177/09504222211023419

For more information about UCLan's research in this area go to http://www.uclan.ac.uk/researchgroups/ and search for <name of research Group>.

For information about Research generally at UCLan please go to http://www.uclan.ac.uk/research/

All outputs in CLoK are protected by Intellectual Property Rights law, including Copyright law. Copyright, IPR and Moral Rights for the works on this site are retained by the individual authors and/or other copyright owners. Terms and conditions for use of this material are defined in the policies page.

\section{CLoK}

Central Lancashire online Knowledge www.clok.uclan.ac.uk

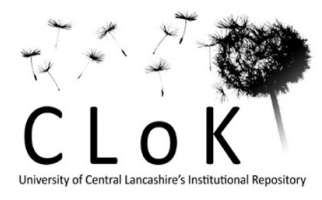




\title{
Title: Account of Practice -
}

\section{Lessons learned by educator and students through experiential entrepreneurship}

\begin{abstract}
This account of practice describes an experiential learning approach used for Enterprise and Entrepreneurship education in a UK higher education setting. Module design and delivery insights describe the methods employed by an entrepreneur turned educator to facilitate learning via popup shop / event activities financed by a $f 50$ seed fund. Feedback showed the approach was highly valued by students who reported significant personal development and enhanced entrepreneurial understanding. Considerably improved student attainment was also measured. The educator reflects on how his experiences as an entrepreneur helped shape the activities and their delivery, and the impact on his own pedagogical and academic development.
\end{abstract}

\section{Introduction}

Interest in Enterprise and Entrepreneurship (E\&E) in UK Higher Education has increased significantly in recent years. Numerous modules have been added to courses within business schools and throughout many subject areas across many faculties. This inevitably gives rise to questions about the suitability and success of such provision. What methods of E\&E education are being delivered, by whom and with what effect?

The QAA guidance for UK Higher Education Providers on Enterprise and Entrepreneurship Education recommends various approaches, and in their most recent update (QAA, 2018) they attempt to draw together and promote best practice. When considering delivery methods, a clear distinction is made between students learning ' $a b o u t$ ', learning 'for' and learning 'through' (E\&E).

Learning about E\&E theories, case studies and knowledge may be regarded as a 'traditional' academic approach where students are prepared for employment or further study. Whereas learning for, and to a greater extent, through entrepreneurship requires students to engage in more practical activities aimed at acquiring entrepreneurial skills and awareness in preparation for becoming an entrepreneur or working in entrepreneurial organisations.

There is considerable pedagogical debate about effective methods for E\&E education in higher education settings. Many have written of the value of experiential learning, which aligns with teaching for and through entrepreneurship. But what does this look like in the classroom for the E\&E educator? What different skills are required when delivering in this way? Perhaps most importantly, what impact do such methods have on students?

An example of experiential learning in E\&E education lies at the heart of this Account of Practice (AoP). But there is a twist. The author's perspective is not of a seasoned academic judiciously implementing principles of experiential learning, but of an experienced 
entrepreneur embarking on his first full-time year of lecturing. When designing the module delivery, the author did not have the knowledge he has since gained about E\&E education pedagogy. The educator knew very well the joys and challenges of being entrepreneurial, and the skills required, but was untrained in education and unaware of the approaches employed by other E\&E educators.

\section{Background to the module}

Working part-time in my first year as a lecturer I delivered a year 3 undergraduate module called 'Managing Your Business'. But I found its content far removed from my experience of what it takes to start and run a business. How could something as dynamic and practical as starting a business be presented as dry and theoretical? This was learning about entrepreneurship without any real understanding of why or how? Students appeared unengaged throughout the module, which equipped them with few entrepreneurial capabilities. Very disappointing. But if this E\&E module was not fit for purpose, how should it be changed?

Inspiration came from a small pop-up activity towards the end of the module. It was isolated from other content, and not assessed, but was the only time I observed enthusiastic students talking and acting in a business-like manner. I knew from my own experience that essential business activities like decision making, problem solving, teamwork, buying, selling and making a profit or loss can all be experienced in a very real way, even by the smallest of entrepreneurial activity. I therefore decided to place the pop-up concept at the heart of the module redesign.

As a novice educator I sought guidance from my line manager and was given support for the idea and freedom to experiment with delivery, as long as the existing learning outcomes for the module were met. I now realise this freedom to innovate was in some part due to the module being elective, so it was not 'owned' by any course and no one had visibility of what I was doing, so my experiment proceeded without any academic oversight.

The elective 20-credit module was delivered in the 2017/18 academic year over two semesters at a UK university. Thirty-four students took the module, of whom 28 were UK nationals living within a 30-mile radius of the university and six were visiting Chinese nationals. Approximately one in three were female. As an elective module, students had made a conscious decision to study issues around business start-up.

\section{Module delivery}

When I received my teaching contract I had just a few days to prepare, so the simplest option would have been to carry over the old content from the previous year. In fact, if strict adherence to the University quality systems was the goal, then all delivery and assessment decisions would have been made and published many weeks before I received my contract. But instead, I sketched out a new structure and often created new content on 
the day of each weekly session. In hindsight, this lack of planning helped because I could adjust the topics covered and the approach taken depending on how the new format was progressing. For example, it became clear that most teams were unsure how to approach pricing their products or events, so I created a session on pricing to provide some structure for their decision making.

I introduced the module concept in the first week, informing students they were required to work in groups, which drew some inevitable rumbles of discontent. These were third year students who didn't want their degree grade disrupted by less motivated or able team members. But the mood soon changed as I introduced the pop-up concept. Working in groups of six they were to run two pop-up shops or events, one in each semester. To add realism, I secured $£ 300$ from the business school to invest a $£ 50$ 'seed fund' into each of the six teams. The money could be spent on anything that contributed to the pop-up but must be paid back upon completion of the module. At that point there was a tangible buzz in the room, a real feeling of excitement. The idea of the business school not just teaching students, but investing in them, seemed to instantly grab attention and created tremendous buy-in to the task. From that point on it was striking how few interpersonal issues arose with any groups compared to other group activities on other modules I teach.

Students formed teams based on who they happened to be sitting with on the first day. It was an elective module for many courses, so each team consisted of some friends and some strangers.

In the first session the newly formed teams had an hour to start thinking about what their pop-up shop or event could be. Little restriction was placed on the activities which could be chosen, as long as they were legal, ethical and practical. I did not want to be too prescriptive, as I knew the decision-making process would provide a valuable learning opportunity. The fall-back position was a standard cake sale, but I encouraged students to be more creative, especially in the opening session when time was on their side.

As the first session progressed, I could see that students seemed genuinely excited, which was a great relief to me. Just because I thought this was a good idea, I had been nervous when starting the session, unsure how it would be received, especially given my lack of teaching experience and training. But my excitement about delivering a 'proper' practical entrepreneurship experience seemed to be matched by student's appetite for it. In fact, there was a frenzy of popup ideas being thrown around creating a cacophony within the room only just big enough to house its occupants. With some reluctance, and no little difficulty, it was time to bring the first session to a close by encouraging students to keep their ideas flowing outside the classroom, so the better concepts could be discussed in more detail next week.

In the weeks that followed, my role was closer to a small business coach than a lecturer; a role I was happy to take. I rotated between groups discussing and assessing different ideas, pointing out various strengths and weaknesses, along with what issues they should consider before deciding which idea to go ahead with. Students were encouraged to think of potential problems associated with some ideas, or the opportunities that other ideas 
presented, such as coinciding with key dates like the build-up to Christmas or Valentine's Day.

There was often an understandable naivety in thinking through the practical implications of potential popup options, with students frequently underestimating the complexity of early ideas. I attempted to strike a balance between steering students away from poor decisions, while also allowing them to discover issues themselves, so learning from them. For example, some teams became set on ideas which had clear challenges, which were pointed out to them, but ultimately the decision was theirs.

In fact, difficulties with decision making was a common problem. Many students were so concerned about making wrong decisions, that they took far too long to make simple choices, which then had a knock-on effect to their schedule. I did not want to solve problems for them, so encouraged a pragmatic approach focused on taking action and learning quickly from any mistakes. Many students commented positively on this aspect of decision making, with one saying:

"I feel I have significantly developed my ability to make important decisions through gaining experience across both pop-ups by making mistakes and learning from them."

One issue faced by all teams was booking space for their popup activity. Teams were advised to book as soon as possible to avoid predictable problems, like limited availability. But teams were not informed of the variety of possible restrictions that various venues might impose, other than the need for risk assessments. For many teams an apparently simple booking task turned into a voyage of discovery. Lack of availability on preferred dates or restrictions on electrical equipment were typical of the problems encountered and learnt from.

The popup activities ranged from raffles, quizzes, Nerf gun shooting and online FIFA tournaments, to selling Chinese pancakes and, yes, one cake sale. The idea I had most concerns about initially was the FIFA tournament, due to my lack of knowledge in this kind of gaming activity, and the tournament business model which used a percentage of entry fees as prize money. I questioned the team carefully about the activities and logistics, including how entry fees would be collected and prize money given out, and was impressed with their detailed answers and obvious enthusiasm, so was happy for the team to proceed. This turned out to be a very successful popup and the only one that utilised technology to make a physical venue unnecessary.

All profits made by the popups were to be paid to a charity chosen by each team. The primary reason for this was to avoid any possible issues with non-UK student visa restrictions on running a business. It would also reduce the risk of funds being mis-used as proof of payments to charities was required in the final assessment.

The charity selection process was designed to be viewed from a business perspective. Factors like the charities' brand awareness among students and availability of point of sale materials were to be considered to mimic aspects of choosing a franchise. However, in 
practice, group discussions often revealed some very personal reasons behind the charities closest to different students, which had a significant bonding effect on some teams. This had not been anticipated but appeared to be more beneficial than choosing a charity simply based on marketing or branding criteria. Later, I noticed that very personal charity connections seemed to embolden students to sell their products or events to customers (mostly students) more confidently by providing an altruistic purpose to the commercial activity.

The $f 50$ seed funds were given out in week three. Handing over the cash to each team felt like a very significant moment for me and the teams. Every team member signed a 'team contract' which reinforced the requirement to pay back the investment. I was pleased to see how this formality added further authenticity to the task, as did the responsibility the students had to use the funds effectively. Deciding how to best spend hard-earned investment funds in order to return a profit is at the very core of the entrepreneurial experience and undoubtedly stuck a chord. This realism was appreciated and commented on by many students, with this being a good example:

"Becoming an entrepreneur and owning my own business has always been my dream. This experience was like a trial to me, it gave me feel of what it would be like operating my own business. It put me in the right mind-set of a real entrepreneur."

I have subsequently become aware of many examples of pop-ups used in E\&E education, with Mason and Arshed (2013) being an excellent example and bearing many similarities to the approach I took. Most examples feature smaller, or even zero, team investments where students must literally create something from nothing. It may seem attractive to believe this encourages greater creativity and resourcefulness, but it may inadvertently provide an unfair advantage to students with greater access to personal financial resources. Unexpectedly, the seed fund had the additional benefit of inclusivity by creating a level financial playing field.

The university business incubator provided a bookkeeping workshop so each team could maintain accurate records of expenditure and sales, so enabling calculation of profit or loss. Here I started to see another unplanned positive. Bookkeeping and accounts are a necessary but often disliked activity, but out of each team emerged a happy, even proud, student willing to take responsibility. Gradually I became aware of other tasks being aligned very effectively to personal preference and capability. Some students took on customer facing roles making bookings or selling products, while others beavered away behind the scenes researching or making products. Thus, less academically gifted students were finding roles every bit as valuable to their team as students with strong scholarly skills, so another form of inclusivity had unexpectedly been achieved.

As the weeks progressed, and with some encouragement, each team became more organised. Ideas became more focussed, decisions were made and actions taken. Most students managed this transition well and began talking and acting in a more business-like manner. 
Each popup event or shop took place outside the classroom, and this is where I believe the greatest E\&E education took place. I was not able to visit every popup, but the activities, and the learning from them, were well documented in the two written assessments. I began reading about typical business problems, like suppliers letting teams down, hard work, mistakes, frustration and last-minute efforts into the night. But I also read of enjoyment, teamwork, pride and satisfaction.

One student wrote about the quiz night popup her team ran. This feedback encapsulates the essence of what I had hoped the redesign would achieve - the experience of hard work and personal fulfilment related to starting a new business i.e. being entrepreneurial:

"Being involved in the formation and operation of a business idea devised by myself was truly rewarding. The amount of time and hard work it took to develop and execute this plan was very much worthwhile, when I saw, students coming together on a night out, enjoying themselves having fun whilst also creating money for a good cause was beyond great satisfaction."

One important capability for anyone in business is to learn from mistakes. The idea of running two pop-ups was for students to learn lessons from their first attempt and make improvements second time round. But this expectation was not always met. It seemed that some teams found it much less exciting to repeat and refine an idea than creating it in the first place. As a result, the second semester failed to reach the same levels of excitement generated previously. It is also likely that other final year, final semester assessment demands competed for student's time and attention.

The teams that had worked very effectively on the first pop-up struggled to repeat the levels of energy and performance they had before. By contrast, teams which encountered significant problems or performed poorly on the first pop-up seemed more determined to make amends second time round. There appeared to be greater motivation to fix problems or rectify mistakes than to achieve higher performance and larger profits.

The two written assessments, required by the module descriptor, were not necessarily best suited to evaluating entrepreneurship. As a result, students with the strongest academic writing skills out-performed others with stronger entrepreneurial skills. For example, the team which made and sold traditional Chinese pancakes found out close to the date of the popup that they were not allowed to prepare food within the University space they had booked. This potentially disastrous situation was turned around by building a simple online ordering app, allowing them to deliver pancakes they made off-site. This highly effective innovation led to more sales and bigger profits than any team, so clear winners in the traditional measure of entrepreneurial success.

Naturally I applauded their entrepreneurial actions and anticipated an excellent write-up for the assessment. Disappointingly, their inability to write effectively about their wonderful experience resulted in distinctly average marks. Furthermore, a well written, critical and insightful reflection of a poorly run, loss-making pop-up gained high marks for the student. As an entrepreneur, I found this deeply frustrating. But to balance the debate, one student provided some wonderful insight when reflecting on the educational value of being able to 
experiment and make mistakes, enabling them to better explore their entrepreneurial capabilities.

"It is better to learn where we go wrong in business this way than in the real work environment in the future. It is best to learn now while we have the resources and support to improve and be willing to take risks."

As valuable as this reflection is, there must come a point in E\&E education where the capability of a student to be entrepreneurial and create value must be of greater significance than the ability to reflect intelligently on yet another failure.

\section{Outcomes}

From a task point of view, each group successfully paid back the $f 50$ investment, which was then set aside to fund the next year's delivery. This process has been repeated in following years, so the original $£ 300$ has now funded four years delivery, indicating the module design can be self-financing, following the initial investment. Additionally, just over $£ 900$ profit was generated by the student teams and donated to their chosen charities.

Academic attainment improved with average grades rising from 54 prior to the changes to 62 afterwards. This advanced the average student from 2:2 to 2:1, with the improved attainment level maintained in following years.

But the biggest success in this classroom was the overwhelmingly positive impact on students, which they expressed through reflective statements. The volume, quality and insight of the feedback was quite astonishing and clearly demonstrates the value gained by students from this approach. A small sample of unedited (warts and all) excerpts included throughout this AoP.

It was interesting just how effective learning through entrepreneurship was, and how something as simple as a pop-up shop could embed learning so effectively:

"I have read about creating a business before, but until experienced for myself, it did not quite resonate. I now know what would be expected and have a frame of reference to look back on if I choose to create another business."

Some students considered the contrast between the learning from theory-based lessons about business concepts that they were accustomed to and the understanding they gained through their practical experience:

"This is one of the only course at university that I have which gives students real life experience of business. It allows us to put everything we have learned through university into action."

Many students commented on the positive impact the exercise had on their personal development: 
"I even got over some of my fears, such as having the confidence to trust my own opinion and just believing in myself."

A number of students valued the experience of being taught by an entrepreneur:

"[The tutor's] first hand knowledge he supplied us with gave us an insight into just how a business is run, and concepts we must pay attention to in the real world."

Several students also commented on how much they valued the module.

"This module is a truly fantastic opportunity for students to experience starting a business and what it takes. I will be highly recommending it to other business students at the University. It is an asset to the business school."

\section{Delivery insights}

The significantly improved academic results and remarkable student feedback indicates this exercise, where students learned through entrepreneurship, provided great educational and developmental value. As an E\&E educator I found delivering this module exhilarating, especially once I saw the student feedback confirming the positive reactions I had already observed. What could be more rewarding for an educator than students performing well, while valuing and enjoying what they are learning and the way they are learning it?

I would like to think that any E\&E educator with a keen interest in entrepreneurship could deliver this module successfully. In fact, a colleague with considerable enterprise experience, but little teaching experience, taught the most recent deliveries of this module with similar success, despite the onset of Covid-19. So it appears that the design of the popup tasks with the seed fund provides a strong and repeatable delivery platform.

Frustratingly, further developments have been limited by the kind of work restrictions many academic readers will be familiar with. Unfortunately, several factors contribute to the possibility that the changes described in this AoP may be abandoned in the future.

The University quality processes stipulate significant changes to a module starting in September must be approved nine months earlier in January. This is sensible for course administration but conflicts with experimentation. No matter how promising changes may appear in their first delivery, it would be premature to commit to them $100 \%$ when the test is just $50 \%$ complete, as was the case with this two-semester module. As a result, changes to learning outcomes to facilitate greater alignment of assessment to entrepreneurial outcomes could not be completed for the second delivery.

I also encountered a reluctance to commit in writing to the $f 50$ team investment, which was a vital part of the module experience and probably the most successful innovation. The cost was considered administratively and financially problematic, as the module is delivered across three campuses, one of which is an international campus outside the UK. However, the original $£ 300$ acquired in 2017 remains in circulation and the investment of $£ 50$ per 
team spread over four years now equates to just $f 12.50$ per team and just a few pence per student.

Unfortunately, workload pressures on other courses necessitated my move away from the module after two deliveries, despite my desire to continue its development. The new module delivery lives on at one campus, but it is not formally documented so its future is not secure. I have informally passed on the lessons I learned to another lecturer to deliver, but fear for its future unless the new features can be more formally adopted through the periodic course review process.

Regardless of the future of the redesigned module, my own experience with the module has greatly enhanced my development as an E\&E educator. Drawing inspiration from the outstanding student feedback I wrote a small, informal case study for the business school to share the enthusiasm students had for this style of learning and its positive impact on attainment. The case study progressed to several conference presentations, my successful HEA fellowship application and now a journal article. To paraphrase an entrepreneurship mantra, it's been a good academic return on investment.

On reflection, it is interesting that an entrepreneur with limited teaching experience, no teacher training and little academic support was able to diagnose the problem with an E\&E module and implement such a successful solution. Academics excel at theory, which in many ways it is their raison d'être, but this can create a predilection for teaching about entrepreneurship, which was the problem I set out to solve for this module. Whereas my natural inclination as an entrepreneur was to prepare students for entrepreneurship by focussing on behaviours, attitudes and competences acquired by learning through entrepreneurship. I hope this example allows others to draw inspiration from such a simple yet effective structure for E\&E education.

I believe the QAA guidance perfectly summarises the aim of E\&E education and, in my view, what E\&E education should help students achieve: "in short, having an idea and making it happen" (QAA, 2018: 9).

\section{References:}

QAA, 2018. Enterprise and Entrepreneurship Education: Guidance for UK Higher Education Providers, s.I.: QAA Publications.

Mason, C. \& Arshed, N. (2013). Teaching entrepreneurship to university students through experiential learning. Industry and Higher Education, Vol 27, No 6. pp. 449-463. 